Disponível em

http://www.anpad.org.br/rac

RAC, Rio de Janeiro, v. 18, n. 6, art. 1, pp. 748-771, Nov./Dez. 2014

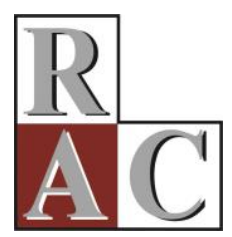

\title{
Estação de Transbordo de Cargas como Mediador da Logística de Fertilizantes
}

\section{Cargo Transshipment Stations as Logistic Mediators for the Fertilizer Industry}

Roberto Giro Moori E-mail: roberto.moori@mackenzie.br Universidade Presbiteriana Mackenzie Rua da Consolação, 896, 01302907, São Paulo, SP, Brasil.

Alessandro Riquetti E-mail: alessandro.riquetti@gmail.com

Universidade Presbiteriana Mackenzie Rua da Consolação, 896, 01302907, São Paulo, SP, Brasil. 


\title{
Resumo
}

Para atender o competitivo mercado mundial dos alimentos, as empresas do agronegócio brasileiro têm alargado as fronteiras agrícolas para regiões cada vez mais distantes das áreas de consumo, o que faz da logística, imprescindível. Nesse sentido, este artigo teve como objetivo verificar a importância das estações de transbordos de cargas como variável mediadora entre a gestão integrada da logística e seu desempenho em empresas brasileiras do ramo de fertilizantes de origem mineral. Para tanto, realizou-se uma pesquisa descritiva em que, para coletar dados, utilizou-se de questionários semiestruturados aplicados junto a gestores de logística. Foram obtidas 89 respostas. Os dados foram submetidos à modelagem em equações estruturais, o PLS-PM, em nível de significância estatística $(\alpha \leq 0,05)$, revelou que as estações de transbordos de cargas medeiam parcialmente a relação entre gestão integrada da logística de fertilizantes e seu desempenho. O resultado obtido mostrou a aderência do modelo teórico estabelecido e evidências de que a utilização das estações de transbordos de cargas de fertilizantes como fator mediador pleno, ainda, tem um longo caminho a ser percorrido.

Palavras-chave: gestão integrada da logística; estações de transbordos de cargas; desempenho logístico; fertilizantes.

\begin{abstract}
In order to participate in the competitive global food markets, Brazilian agribusiness has been expanding its agricultural frontiers to regions ever more distant from the consumption area, which makes logistics management absolutely necessary. Accordingly, this article verifies the importance of cargo transshipment stations as mediating variables between integrated logistics management and logistics performance in Brazilian companies that are part of the mineral fertilizer industry. Thus, a descriptive study was carried out in which data was collected by semistructured questionnaires applied to logistic managers. Eighty-nine responses were obtained. The collected data was submitted to structural equation modeling, PLS-PM, at $(\alpha \leq 0,05)$ statistical significance level, and revealed that cargo transshipment stations partially mediate the relationship between fertilizer companies' integrated logistics management and performance. The results showed adherence to the established theoretical model and that the use of cargo transshipment stations as a full mediator for fertilizers still has a long way to go.
\end{abstract}

Key words: integrated logistics management; cargo transshipment station; logistics performance; fertilizers. 


\section{Introdução}

A crescente demanda por grãos a preços competitivos tem levado os produtores brasileiros a buscarem áreas de terras para o cultivo, de baixo custo, situadas cada vez mais distantes do mercado consumidor. As terras brasileiras com limitações de fertilidade natural decorrentes da acidez do solo, especialmente, aquelas situadas nas regiões de cerrados, tornam-se altamente produtivas com manejo adequado e uso de fertilizantes, ações aliadas à época propícia de plantio (Nicolella, Dragone, \& Bacha, 2005). Como consequência, o mercado brasileiro de fertilizantes é o que mais cresce no mundo. Na última década, o país registrou elevação de $6 \%$ nas vendas internas, enquanto o desempenho mundial se situou em $1 \%$. Os fertilizantes somam $30 \%$ do custo de produção para soja e milho, mas, em tempo de alta de preços do insumo, chegam a 40\% do custeio dessas culturas (Silveira, 2012).

Em 2013, para uma produção brasileira de 188,2 milhões de toneladas de grãos (Instituto Brasileiro de Geografia e Estatística [IBGE], 2014), o país consumiu 31,1 milhões de toneladas de fertilizantes. Do total consumido em 2013, foram importados 21,6 milhões de toneladas de fertilizantes intermediários correspondentes a micro e macronutrientes como amônia, ureia e cloreto de potássio (Associação Nacional para Difusão de Adubos [ANDA], n.d.a). Os portos brasileiros são capazes de receber os fertilizantes intermediários, no entanto os custos podem ser elevados dependendo da localização e entrega dos produtos. Por conta disso, os principais portos de entrada dos fertilizantes intermediários são os das cidades de Santos (SP), Vitória (ES), Rio Grande (RS) e Paranaguá (PR) (Banco Nacional de Desenvolvimento Econômico e Social [BNDES], 2010a).

A movimentação de fertilizantes, da entrada nos portos até as fazendas produtoras de grãos, cujo fluxo simplificado é visualizado na Figura 1, é predominantemente realizada pelo modal rodoviário e, em menor quantidade, pelo modal ferroviário (BNDES, 2010a); e a depender do corredor logístico escolhido, a distância da origem ao destino do escoamento de grãos e do fertilizante pode variar de $400 \mathrm{~km}$ a $2.000 \mathrm{~km}$ (Michelon, 2007; Salin, 2013). Corredor logístico, segundo Rodrigue, Comtois e Slack (2006), é o resultado de combinações de estações de transbordos intermodais e das adequadas infraestruturas para o transporte de produtos.

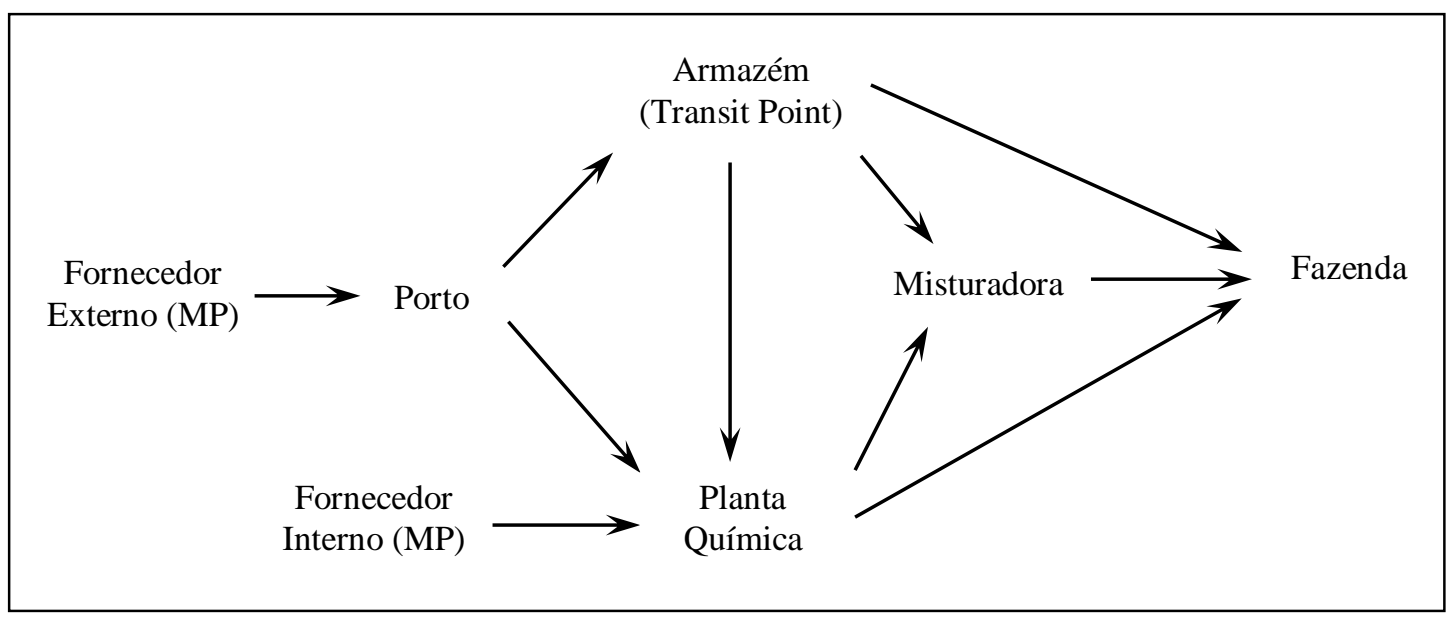

Figura 1. Fluxo Simplificado de Movimentação de Fertilizantes do Porto para a Fazenda.

Fonte: elaborada pelos autores.

Um programa tecnológico e de procedimentos para melhorar o transporte intermodal dos países da União Europeia (Promoting Innovative Intermodal Freight Transport [PROMIT], 2007) analisa a logística intermodal mediante a combinação de transportes e estações de transbordos de cargas em três níveis. No nível 1, analisa a localização dos pontos de origens, destinos das cargas e tempos de trânsito para atender o desempenho ou êxito de atendimento ao cliente. No nível 2, analisa o transporte como um conjunto de recursos ou serviços logísticos como escolhas de modais, armazéns, corredores logísticos, sistemas de informação e estações de transbordos de cargas. Pode ser denominada de gestão 
integrada dos recursos ou serviços logísticos. No nível 3, as operações da gestão integrada (ou serviços logísticos), como carregamento, descarga, armazenagens, manuseio e movimentação de produtos, são vistas em detalhes.

O modelo PROMIT (2007), com as devidas adaptações para o fluxo simplificado apresentado na Figura 1, é representado na Figura 2.

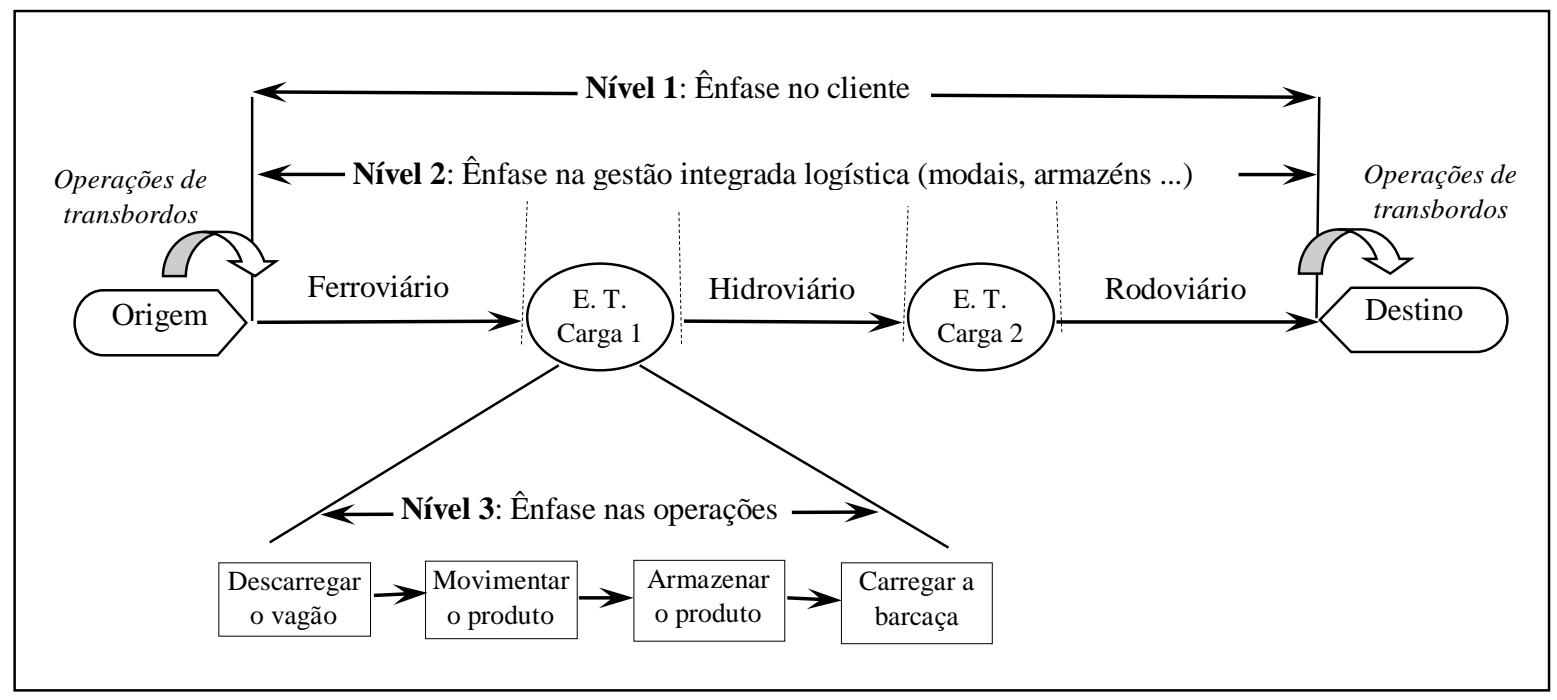

Figura 2. Níveis de Análise da Logística Intermodal.

E. T. Carga que aparece na Figura, abreviado, significa Estação de Transbordo de Carga.

Fonte: Adaptado de Promoting Innovative Intermodal Freight Transport. (2007). D 4.1: European benchmarks in intermodal transport. Retrieved from http://www.promit-project.net/UploadedFiles/Deliverables/D4_1.pdf

No Brasil, nos últimos 10 anos, o governo tem tomado iniciativas para garantir a competitividade das commodities agrícolas como o Plano Nacional de Logística Terrestre (Ministério dos Transportes, n.d.) para equilibrar a matriz de transporte, atualmente, concentrada em rodovias; a Lei Geral dos Portos (Decreto n. 8.033, 2013), de modo a permitir que as empresas privadas também participem da infraestrutura logística em Instalações Portuárias Públicas de Pequeno Porte e dos grandes e estruturados portos públicos.

Vários projetos de estações de transbordos e instalações portuárias para o escoamento de grãos estão concluídos, outros encontram-se em andamento e há aqueles em que a obra ainda está por começar, incluindo os que permitem o retorno com fertilizantes, sementes ou herbicidas às áreas agrícolas (Secretaria de Portos, n.d.).

Portanto, inspirado no modelo abstrato de análise da logística intermodal europeu (PROMIT, 2007) e nas iniciativas brasileiras para os investimentos logísticos para evitar a descontinuidade da cadeia produtiva e, em consequência, obter maior rapidez e eficiência nos deslocamentos das commodities agrícolas, desde a sua origem nos campos de cultivo até o seu destino final (Garrido, 2011), este estudo teve como problema de pesquisa resolver a seguinte questão: a estação de transbordo de cargas de fertilizantes medeia a relação da gestão integrada dos recursos logísticos e seu desempenho? O objetivo foi o de compreender aspectos das estações de transbordos de cargas, como a agilidade e custos no manejo e operações de carregamento e descarregamento para atender as metas de desempenho logístico do produto fertilizantes.

Este estudo está estruturado da seguinte maneira: após a introdução, são apresentadas a revisão bibliográfica e respectivas hipóteses. Nas seções seguintes são abordados os procedimentos metodológicos, análises estatísticas dos dados e as discussões de resultados. Por fim, nas últimas seções são apresentadas as principais conclusões, suas implicações, sugestões para pesquisas futuras e as referências bibliográficas utilizadas no estudo. 


\section{Modelo Conceitual e Hipóteses}

\section{Gestão integrada logística e o desempenho}

A análise cuidadosa da literatura sobre gestão logística revela a diversidade de embasamento teórico e de definições envolvendo aspectos de recursos físicos e tecnologias de informação com pouca concordância entre os autores (Mentzer, Min, \& Bobbit, 2004).

A matriz mais comum aponta a gestão logística como um processo de planejamento, controle e avaliação para movimentar produtos, que vai desde o ponto de origem até o ponto de consumo final para adicionar valor, de tempo e lugar, e obter desempenhos superiores aos dos concorrentes (Ballou, 2010; Bowersox \& Daugherty, 1995).

Os recursos envolvidos em atividades logísticas são variados. Para Bowersox e Closs (2001), os recursos mais importantes são: a informação, previsões, gerenciamento de estoques, infraestrutura de transporte, movimentação de materiais e embalagem. O Council of Supply Chain Management Professionals (CSCMP, n.d.) considera como essenciais: o processamento de pedidos, as estocagens, tráfego e transportes, escolhas de locais para a fábrica, os armazéns e o manuseio de materiais.

A localização geográfica dos centros de distribuição, fontes de matérias-primas, armazéns de estoque de produtos em processos e acabados que movimentam em torno das instalações da empresa tem sido tratada estrategicamente, dada a sua importância para equilibrar os diversos custos logísticos e manter os níveis de serviços prestados aos clientes (Coyle, Bardi, \& Langley, 2003; Simchi-Levi, Kaminsky, \& Simchi-Levi, 2003).

Com a competição crescente, os armazéns, geralmente situados em locais de fácil acesso, como os entroncamentos rodoviários, têm se tornado um importante elemento para a redução de custos logísticos. A mudança de visão do armazém como um recurso para a estocagem de produtos de longo prazo para uma visão de curto prazo fez com que o tempo de permanência dos produtos fosse reduzido de meses para poucos dias, ou até mesmo horas (Coyle et al., 2003).

Para viabilizar a redução dos estoques, a tecnologia da informação (TI) tem desempenhado importância fundamental no sentido de reunir, agrupar e analisar os dados de forma rápida e consistente. Sem tecnologia da informação seria inviável conseguir uma sinergia eficiente entre os recursos logísticos (Meixell \& Norbis, 2008). A informação atua como um direcionador da cadeia de produtiva, de modo a fazer com que todos os atores trabalhem de maneira conjunta, integrada e coordenada (Chopra \& Meindl, 2001). Para Griffis, Goldsby, Cooper e Closs (2007), em qualquer empresa, as medidas de desempenho são essenciais para uma efetiva gestão.

Empresas que acompanham o desempenho de forma eficiente e conjunta com métricas estratégicas têm maior compreensão da cadeia de suprimentos e da causa do desempenho obtido (Coyle, Novak, Gibson, \& Bardi, 2011).

Assim, nos deslocamentos de produtos, há de se supor que:

$\mathbf{H}_{1}$ : Existe relação positiva entre gestão integrada da logística e seu desempenho.

\section{Gestão integrada da logística e a estação de transbordo de cargas}

A movimentação de produtos por meio de estações de transbordos de cargas tem sido crítica para o desenvolvimento econômico brasileiro e oferece a utilidade de não isolar a cadeia produtiva (Fleury, Wanke, \& Figueiredo, 2000). A mudança do modo de transporte rodoviário para outro, ou para a combinação de vários deles, só é viável com a devida adequação da carga aos requisitos dos embarcadores, o que nem sempre é tarefa fácil (Blauwens, Vandaele, Voorde, Vernimmen, \& Witlox, 2006). Assim, se o cliente exigir velocidade na entrega do produto, a escolha do modo de transporte 
ficará restrita, descartando os modais mais lentos, mesmo que de menores custos (Jeffs \& Hills, 1990). No processo de escolha de modal, os fatores mais importantes para os embarcadores de granéis agrícolas brasileiros são o preço do frete, velocidade de entrega e confiabilidade dos serviços (Dalmás, Lobo, \& Rocha, 2009).

Segundo PROMIT (2007), as maiores barreiras para o transporte intermodal são: o envolvimento de muitos parceiros de negócio como operadores de ferrovia, rodovia, ineficiência dos descarregamentos, manejo e carregamento de produtos nas estações de transbordos com tempo de espera elevado, incompatibilidade entre veículos e equipamentos de carga e descarga, falta de padronização das unidades de carregamento, diferenças entre bitolas das linhas ferroviárias, velocidade dos trens, que ainda é muito baixa, e falta de informação sobre os serviços disponíveis.

Para as estações de transbordos operarem produtivamente, além de máquinas e equipamentos, deve-se contar com uma mão de obra capacitada e treinada (Teller, Guimarães, \& Roessing, 2007), pois o desenvolvimento de habilidades logísticas para utilizar equipamentos especiais ou customizados para a movimentação de carga, armazenagem e descarga (Coyle et al., 2003) é essencial para o desempenho da empresa (Fawcett, Stanley, \& Smith, 1997).

Outro fator determinante nas atividades logísticas é o tamanho do lote a ser movimentado, que deve ser analisado sob o ponto de vista do trade off entre custo do frete e o custo do inventário em trânsito. Enquanto os estoques estiverem em trânsito ou até chegarem ao destino e não forem consumidos, eles acumulam, além do próprio custo, o custo de transporte, custo de oportunidade perdida, de manuseio, do espaço alocado (Sheffi, Eskandari, \& Koutsopoulos, 1988) e demais custos relacionados a risco e obsolescência do produto (Ballou, 2010).

Assim, nos deslocamentos de produtos, é de se supor que:

$\mathbf{H}_{2}$ : Existe relação positiva entre gestão integrada da logística e estação de transbordo de cargas.

\section{Estações de transbordos de cargas e o desempenho logístico}

A gestão logística, segundo Ballou (2010), deriva unicamente do transporte. As demais atividades logísticas são resultados de fenômenos econômicos e de mercado. Como tal, na gestão logística, o transporte não pode ser considerado de maneira isolada. Assim, a tecnologia da informação é a grande aliada na obtenção da eficiente sinergia na intermodalidade (Meixell \& Norbis, 2008). Além do custo de transporte, devem-se levar em consideração outros custos logísticos como as demoras para carregamento, descarregamento e manejo nas estações de transbordos, o tempo de deslocamento no modal escolhido e o impacto do estoque do produto em trânsito (Coyle et al., 2011).

Ao considerar a variável estoque em conjunto com o custo do transporte, pode-se chegar, em alguns casos, à decisão que, ao optar por um modal de menor custo e mais lento, o estoque que ficará imobilizado por vários dias poderá tornar a operação menos competitiva do que se imaginava inicialmente, uma vez que o custo do estoque será altamente representativo (Coyle et al., 2011).

Estações de transbordos de cargas, sobretudo as de grande escala, normalmente, não são competitivas em curta e média distâncias. Quando se leva em conta o tempo de operação de transbordo mais o tempo de transporte, o transporte direto é mais rápido e de menor custo. Em contrapartida, em longa distância, as estações de transbordos intermodais tornam os produtos competitivos, principalmente se a maior parte do percurso for realizada pelo transporte ferroviário, em que o custo ferroviário somado ao da operação da estação de transbordo e trecho final rodoviário é menor do que enviar a mercadoria diretamente por rodovia (Woxenius, 1997).

Acrescenta, ainda, Campbel (1992), que a escolha das estações de transbordos, em termos de facilidades e capacidades oferecidas, é importante para o desempenho do sistema logístico da empresa.

Assim, nos deslocamentos de produtos, é de se supor que: 
H3: Existe relação positiva entre estação de transbordo de cargas e desempenho logístico.

\section{Mediação da estação de transbordo de cargas entre gestão integrada da logística e desempenho}

A logística pode ser vista como um sistema que tem como principais variáveis os transportes, armazéns e estações de transbordos, como se pode notar nos problemas de otimização de custos logísticos (Miao, Yang, Fu, \& Xu, 2012). Na busca por soluções de custo mínimo, reduzindo o tempo da entrega e otimizando do processo de transbordo, são desenvolvidos algoritmos em que se consideram as estações de transbordos para as cargas e descargas como se fossem um nó e o trajeto (ligação entre os nós) como se fossem transportes. As fábricas e armazéns são considerados os pontos de origem e destino (Garg \& Prakash, 1985).

A movimentação das mercadorias, desde a origem até o destino, pode ser realizada: (a) como um transporte único; (b) como um transporte multimodal de cargas, ou; (c) como um transporte segmentado ou intermodal. A principal diferença entre o transporte intermodal e o multimodal, segundo Silva (2008), diz respeito à responsabilidade do transportador. Enquanto no transporte segmentado ou intermodal existe a emissão de um documento para cada uma das atividades relacionadas (exemplo: transporte rodoviário, transporte ferroviário, armazéns e transbordo); no transporte multimodal, existe o Operador do Transporte Multimodal (Lei n. 9.611, 1998), responsável por todo o transporte, da origem até o destino, sendo o único ponto de contato com o contratante dos serviços.

Por meio de algoritmo é possível verificar as vantagens logísticas que o transporte multimodal (OTM) pode oferecer, entre as quais, Silva (2008) destaca a utilização de forma mais otimizada da matriz de transporte brasileira, melhor aproveitamento energético por meio de melhor combinação entre os meios de transporte e melhor uso da infraestrutura existente de terminais e manuseio. Os deslocamentos de mercadorias a longa distância realizados por um único modal podem ser substituídos para dois ou mais modais a fim de reduzir custos e adicionar valor.

Nos deslocamentos de mercadorias intermodais, a estação de transbordo atua como variável estratégica que vincula e sincroniza a cadeia produtiva como um processo contínuo, de tal modo que seu efetivo funcionamento contribui, de fato, para a gestão logística adicionar valor, reduzir custos e ser considerada parte do processo de gestão da cadeia de suprimentos (CSCMP, n.d.). A gestão logística tem na estação de transbordo uma variável relevante para a obtenção das metas de desempenho e o reconhecimento de que a logística deve ser vista como um sistema integrado ao domínio do negócio (Stock, Greis, \& Kasarda, 1999).

Assim, nos deslocamentos de produtos que se utilizam de estações de transbordos, é de se supor que:

$\mathbf{H}_{4}$ : Estação de transbordo de cargas medeia o relacionamento entre gestão integrada da logística e seu desempenho.

Portanto, com a estação de transbordo de cargas em estado de operação eficiente, ela tem um papel importante para a movimentação de mercadorias das empresas logísticas. Isso significa que a estação de transbordo (variável moderadora) reduz ou mesmo anula o impacto direto da gestão integrada da logística (variável independente) sobre o desempenho (variável dependente) e, assim, é de se supor que:

H1 $\mathbf{a}$ : A relação direta entre gestão integrada da logística e o desempenho é estatisticamente não significante. 


\section{Procedimentos Metodológicos}

Para testar as hipóteses definidas no referencial teórico, inicialmente, realizou-se um estudo, de natureza exploratória, do tipo qualitativo. Buscou-se, portanto, compreender com mais profundidade o sistema logístico das empresas do ramo de fertilizantes. Para isso, por meio de escalas e medidas desenvolvidas por autores como Griffis et al. (2007) e Blauwens, Vandaele, Voorde, Vernimmen e Witlox (2006), foi desenvolvido um roteiro de entrevistas e estas aplicadas junto a três gestores logísticos de duas empresas de fertilizantes. Os resultados desse estudo serviram de base para a construção de uma versão preliminar do questionário, segundo sugestões de Dillman (2000). Essa versão preliminar foi submetida a cinco respondentes para verificar a sua adequação, redundância e entendimento das assertivas a fim de evitar problemas na coleta de dados.

Após várias alterações e incorporações sugeridas pelos respondentes, definiu-se um questionário definitivo, composto de oito blocos, sendo que o primeiro e o segundo blocos referiram-se a dados demográficos dos respondentes e das empresas. Os blocos três a sete, compostos de 37 medidas, referiram-se aos construtos: Armazém com seis medidas, Localização das Instalações Logística com cinco medidas, Tecnologia da Informação com sete medidas, Estação de Transbordo de Cargas com nove medidas e Desempenho Logístico com 10 medidas. Nesses blocos, foi solicitado ao respondente que assinalasse com um $\mathbf{x}$ na assertiva, o grau de concordância teve uma escala de discordância/concordância que variava de 1 a 6 , sendo Discordo Totalmente (DT) $=1$ e Concordo Totalmente $(\mathrm{CT})=6$. Por fim, o oitavo e último bloco referiu-se a duas questões abertas, a primeira para o caso de o respondente querer complementar alguns pontos não contemplados nas assertivas estruturadas; e, a segunda, para comentários adicionais não relacionados às assertivas como barreiras ou oportunidades relevantes.

Uma amostra de empresas foi extraída do sítio eletrônico da Associação Nacional para a Difusão de Adubo (ANDA, n.d.b), que contava, em 2011, com 122 empresas associadas. Os membros eram grandes produtores de matérias-primas, bem como misturadores regionais de fertilizantes. Inicialmente, fez-se o contato via e-mail, em que se anexou uma carta de apresentação e endereço eletrônico para acessar o questionário disponível no website Survey Monkey, que oferecia facilidades para a elaboração, aplicação e posterior acesso às coletas de dados. Também, foi solicitado que os respondentes fossem membros da área de logística e exercessem cargos de diretoria, gerência ou funções específicas relacionadas à gestão logística, como encarregados e supervisores.

Para o tratamento dos dados coletados, utilizou-se a técnica da análise fatorial, a exploratória e a confirmatória, para validar as medidas e escalas e identificar o construto (ou a estrutura dos dados). Para fazer parte do construto, foram consideradas válidas as medidas com cargas fatoriais iguais ou superiores a 0,7 , ou seja, equivalentes a $50 \%$ da variância explicada (Hair, Anderson, Tathan, \& Black, 2005). A unidimensionalidade dos construtos foi avaliada pela consistência interna dos indicadores de um construto para verificar o ajuste aceitável sobre um modelo de um só fator. Foi medida pelo $\alpha$-Cronbach, sendo o valor 0,7 o limite inferior de aceitabilidade (Chin, 1998). Como a medida da consistência interna assume a unidimensionalidade, mas não garante que ela existe, empregou-se a unidimensionalidade como premissa para obter a confiabilidade composta, que é uma medida de consistência interna do construto. Tal como a medida da unidimensionalidade, o valor de referência para confiabilidade aceitável foi de 0,7 (Chin, 1998).

A validade convergente foi avaliada pelas cargas fatoriais superiores a 0,7 , e pela variância média extraída (AVE), que tem como referência o valor recomendado superior a 0,50 para garantir que as medidas contribuem, significativamente, mais para o seu construto do que para os outros (Fornell \& Larcker, 1981). Na avaliação da validade discriminante, utilizou-se o critério de Chin (1998) e Fornell e Larcker (1981), que considera as medidas adequadas quando a raiz quadrada da variância média extraída (AVE) excede a correlação partilhada do construto com os demais construtos da estrutura.

Definidas a validação das medidas e escalas do construto, empregou-se a técnica da modelagem em equações estruturais, o Partial Least Squares-Path Modeling (PLS-PM), para verificar o ajuste e 
testar a significância estatística dos relacionamentos estruturais dos construtos ao modelo de mensuração. O PLS-PM foi adotado por apresentar as seguintes características: (a) a estimação do PLSPM é baseada em mínimos quadrados parciais; (b) permite utilizar pequenas amostras (Smith \& Langfield-Smith, 2004); (c) admite a ausência de propriedades de distribuição de probabilidade como, por exemplo, normalidade; (d) admite uso de escalas intervalares (Jöreskog \& Wold, 1982); (e) admite utilizar do bootstrapping para avaliar a significância estatística dos coeficientes; (f) permite incluir indicadores de medidas reflexivas e formativas, simultaneamente (Henseler, Ringle, \& Sinkovics, 2009). Diamantopoulos e Winklhofer (2001) argumentam que o uso de medidas formativas deve ser considerado em importância teórica e nas cargas fatoriais, dado que as medidas formativas apresentam problemas de multicolinearidade. Assim, adotou-se o valor limite recomendado para a Tolerância igual a 0,10, o que corresponde a um valor Variance Inflation Factor (VIF) acima de 10 (Hair et al., 2005); (g) permite a predição, ao invés da explicação (Henseler et al., 2009; Jöreskog \& Wold, 1982); (h) admite inferir as forças relativas entre variáveis pelas cargas fatoriais (Fornell \& Laker, 1981); e, (i) permite estimar o ajuste do modelo parcialmente como a medida de ajuste global, o GoF (Godness-of-

Fit) definido pela equação $\left(\mathrm{GoF}=\sqrt{\overline{A V E} * \overline{R^{2}}}\right)$ e o coeficientes de determinação, o $\mathrm{R}^{2}$ (Tenenhaus, Vinzi, Chatelin, \& Lauro, 2005). Wetzels, Odekerken-Schröder e Oppen (2009) sugerem o valor de 0,36 como o valor mínimo para o Godness of Fit (GoF); e Cohen (1977) considera o valor de 0,26 para o $\mathrm{R}^{2}$ como de grande efeito para a área de ciências do comportamento humano e social.

Por fim, para verificar a influência da variável moderadora (M), a estação de transbordo de cargas, na relação entre a variável independente $(\mathrm{X})$, gestão integrada da logística, e a variável dependente $(\mathrm{Y})$, desempenho, empregou-se o método clássico proposto por Baron e Kenny (1986). Segundo Baron e Kenny (1986), a mediação é completa quando o efeito da variável independente sobre a variável dependente torna-se não significante após a introdução da variável mediadora. No entanto se qualquer uma das duas relações, variável independente e mediadora ou variável mediadora e dependente, for não significante, ou ambas, então, não há evidência de mediação (Iacobucci, Saldanha, \& Deng, 2007).

Para a verificação da significância estatística da mediação foram utilizados os testes de Sobel (1982), Aroian (1947) e Goodman (1960). Após, em função das significâncias estatísticas determinadas pelos testes, a mediação foi classificada segundo a tipologia de Iacobucci, Saldanha e Deng (2007), se é completa, parcial ou sem mediação.

Limitações do método: A primeira referiu-se à não convergência de uma base teórica para a validação do construto formativo, como mostram Kim, Shin e Grover (2010) e Petter, Straub e Rai (2007). Não obstante, entre as alternativas existentes, este estudo optou pela de Iacobucci et al. (2007). A segunda referiu-se ao possível viés de respostas dos entrevistados, dada a crença de que as obras de infraestruturas logísticas seriam concluídas no prazo estabelecido e que os entraves legais relacionados à atuação da intermodalidade como o Operador de Transporte Multimodal (OTM) fossem solucionados. A terceira referiu-se ao entendimento do propósito da assertiva pelos respondentes, em razão de o estudo ter abrangido diferentes regiões agrícolas. Portanto os resultados obtidos têm valor restrito à amostra de empresas do ramo de fertilizantes. As possíveis generalizações dos resultados devem ser vistas com ressalvas.

Delimitação do estudo: o estudo foi considerado de concepção transversal e circunscrito às empresas do ramo de fertilizantes, como as misturadoras de fertilizantes, produtoras e beneficiadoras de matéria-prima.

\section{Análises Estatística dos Dados e Resultados}

Foi obtido, no período de fevereiro a abril de 2011, uma amostra composta de 97 questionários ou respondentes. Após uma análise dos preenchimentos dos questionários em relação à completude e às incoerências de respostas, foram descartados oito questionários, restando, assim, 89 questionários aptos para serem utilizados nas análises dos dados. 


\section{Perfil demográfico da amostra}

A amostra, representada por 89 respondentes, apresentou o seguinte perfil demográfico.

1. Com relação às empresas. A amostra de empresas de fertilizantes, filiadas à Associação Nacional para a Difusão de Adubo, segundo a classificação BNDES (2010b), foi constituída da seguinte forma, $83 \%$ eram de grande porte, $8 \%$ e $9 \%$ eram de pequeno e médio portes, respectivamente. Os estados mais representativos da amostra foram São Paulo, com 37\% das empresas, Paraná, com 25\%, e Minas Gerais, com $11 \%$. Os demais estados foram representados com $27 \%$ das empresas. Para o tipo de produção, $70 \%$ eram sob pedido, $20 \%$ por lote e $10 \%$ de produção seriada.

Em resumo, a amostra foi constituída por empresas de grande porte, produção sob pedido e localizadas principalmente nos estados de São Paulo e Paraná.

2. Com relação aos respondentes. Quanto às funções, $58 \%$ eram da área de logística, $27 \%$, de planejamento, $9 \%$, da produção e $6 \%$, de suprimentos. Quanto ao tempo de empresa, $61 \%$ estavam há mais de cinco anos; 25\%, entre 3 e 5 anos; e 14\%, menos de dois anos. Em relação à formação dos respondentes, 53\% eram de administradores; 19\%, engenheiros; 9\%, economistas; 18\%, de diferentes áreas de conhecimento; e apenas $1 \%$ com ensino médio.

Em resumo, o perfil dos respondentes foi caracterizado por pessoas da área de logística, com mais de cinco anos de tempo de empresa, com curso superior, denotando uma boa confiabilidade nos dados coletados.

\section{Validações das medidas e escalas dos construtos}

A partir da amostra de dados, composta de 89 respondentes, depurada pela técnica multivariada, análise fatorial exploratória e confirmatória, após várias rodadas para avaliação, foram obtidas estruturas subjacentes compostas de 23 medidas com cargas fatoriais iguais ou superiores a 0,7, distribuídas nos construtos: Armazém e Tecnologia da Informação, com seis medidas; Localização das Instalações Logística e Estação de Transbordo de Cargas, com três, medidas e; Desempenho Logístico, com cinco medidas. As exclusões das assertivas do construto, dada as baixas cargas fatoriais (menores que 0,7), equivalentes a 14 assertivas ou $38 \%$ do total de 37 , concentraram-se naquelas relacionadas à importância da intermodalidade para escolha de modal menos poluente, de alta produtividade, da melhor qualidade de informação e maior velocidade de entrega; denotando que níveis de serviços e redução de poluentes ainda não eram motivos de inquietação por parte dos gestores logísticos. As medidas depuradas, com suas médias, desvios padrão e cargas fatoriais, são mostradas no Apêndice A.

As quantidades de medidas originais e finais, valores da confiabilidade interna ( $\alpha$-Cronbach), a variância média extraída (AVE) e a confiabilidade composta (CR) são elencadas na Tabela 1. 
Tabela 1

Confiabilidades das Medidas Finais dos Construtos

\begin{tabular}{llccccc}
\hline \multirow{2}{*}{ CONSTRUTOS } & Medidas Originais & \multicolumn{4}{c}{ Medidas Depuradas } \\
\cline { 3 - 6 } & Qtde. Inicial & Qtde. Final & $\alpha$-Cronbach & AVE & CR \\
\hline 1 & Armazém & 6 & 6 & 0,879 & 0,624 & 0,909 \\
2 & Tecnologia da Informação & 7 & 6 & 0,893 & 0,647 & 0,917 \\
3 & Localização Inst. Logística & 5 & 3 & 0,741 & 0,659 & 0,853 \\
4 & Estação de Transbordo & 9 & 3 & 0,681 & 0,604 & 0,820 \\
5 & Desempenho Logístico & 10 & 5 & 0,857 & 0,638 & 0,898 \\
6 & Gestão Integrada Logística* & $(18)$ & $(15)$ & $(0,882)$ & $(0,384)$ & $(0,901)$ \\
\hline TOTAL & 37 & 23 & & & \\
\hline
\end{tabular}

Nota. Fonte: Resultado da pesquisa.

O símbolo de * indica que o construto Gestão Integrada Logística é de $2^{\mathrm{a}}$ ordem.

Observou-se, por meio da Tabela 1, que a "quantidade mínima de três medidas para cada construto" estava de acordo com o mínimo recomendado por Hair, Anderson, Tathan e Black (2005, p. 480) e Iacobucci et al. (2007).

Quanto à confiabilidade das medidas, dada pelo $\alpha$-Cronbach, e da composta, dada pelo CR, os valores obtidos foram superiores ao recomendado de 0,7, denotando a consistência interna dos indicadores dos construtos. Para a validade convergente, avaliada pela carga fatorial e variância média extraída (AVE), apresentou valores acima do mínimo considerado aceitável, que foi de 0,5 , denotando que as medidas dos mesmos conceitos estavam correlacionadas.

Com relação à Gestão Integrada da Logística, que tratou de um construto formativo, de $2^{\mathrm{a}}$ ordem, para determinar a variância média extraída, AVE, e a consistência interna, dada pelo $\alpha$-Cronbach, bem como a confiabilidade composta, CR, o software PLS-PM se utilizou das medidas de $1^{\text {a }}$ ordem representadas pelos construtos: Armazém, Tecnologia da Informação e Localização das Instalações Logísticas. Por conta disso, como era de se esperar, a AVE (igual a 0,384) ficou abaixo do limite recomendado. Não obstante outras análises para a validade convergente como coeficientes estruturais do construto e a multicolinearidade, como apontado por Diamantopoulos e Winklhofer (2001), mostraram-se dentro de valores aceitáveis. A Tolerância e VIF não excederam os valores considerados comprometedores, denotando que o construto não sofreu impacto da multicolinearidade conforme pode ser verificado no Apêndice B.

Foi observado, ainda, que os cinco construtos se correlacionaram de modo positivo e significativo em níveis de $\alpha \leq 0,01$ e $\alpha \leq 0,05$, exceto para Estação de Transbordo e Armazém, elencadas na Tabela 2. Salienta-se que a verificação de correlações bivariadas entre os construtos é uma maneira de se verificar, preliminarmente, a existência de relacionamentos estruturais. Em nenhum caso, o valor da correlação de um construto com os demais foi superior à raiz quadrada da variância média extraída, AVE, conforme se pode ver na diagonal da Tabela 2, denotando a validade discriminante dos construtos. 
Tabela 2

Média, Desvio Padrão e Correlação entre os Construtos

\begin{tabular}{lcccccccc}
\hline CONSTRUTOS & Média & $\begin{array}{c}\text { Dv. } \\
\text { Padrão }\end{array}$ & 1 & 2 & 3 & 4 & 5 & 6 \\
\hline 1. Armazém & 3,43 & 0,913 & $\mathbf{0 , 7 9 0}$ & & & & & \\
2. Desempenho Logístico & 4,46 & 0,914 & $0,577^{* *}$ & $\mathbf{0 , 7 9 9}$ & & & & \\
3. Estação Transbordo & 5,29 & 0,731 & $0,162^{(1)}$ & $0,405^{* *}$ & $\mathbf{0 , 7 7 7}$ & & & \\
4. Gestão Integrada Logística & 3,86 & 0,721 & $0,857^{* * *}$ & $0,648^{* *}$ & $0,285^{*}$ & $\mathbf{0 , 6 2 0}$ & & \\
5. Localização Inst. Logística & 5,24 & 0,847 & $0,524^{* *}$ & $0,454^{* *}$ & $0,293^{*}$ & $0,682^{* *}$ & $\mathbf{0 , 8 1 2}$ & \\
6. Tecnologia da Informação & 3,63 & 1,035 & $0,371^{* *}$ & $0,445^{* *}$ & $0,240^{*}$ & $0,756^{* *}$ & $0,309^{*}$ & $\mathbf{0 , 8 0 4}$ \\
\hline
\end{tabular}

Nota. Os valores da diagonal, em negrito, representam a raiz quadrada da AVE. Fonte: Resultado da pesquisa.

(1) não significante.

O símbolo de * indica que o coeficiente é significante a 5\%; ** a $1 \%$.

Os valores médios dos cinco construtos (Armazém, Estação de Transbordo de Cargas, Desempenho Logístico, Tecnologia da Informação e Localização das Instalações Logísticas) variaram entre 3,43 e 5,29, numa escala de 1 a 6 pontos, e com uma dispersão que oscilou entre 0,721 e 1,035. De todos os construtos analisados, a Estação de Transbordo de Cargas foi a que apresentou coeficiente de variação mais baixo, com o valor de 0,138 [0,731/5,29], denotando baixa dispersão em relação à média. Com relação às medidas dos construtos, foram, na sua maioria, superiores a 3 e indicaram níveis tendencialmente para o lado concordante da escala, denotando que os respondentes demonstraram que a gestão integrada da logística e a estação de transbordo de cargas favoreceram o desempenho logístico. Portanto, com a validação das medidas, escalas e construtos, definiu-se um modelo de mensuração, exposto na Figura 3, para avaliar as relações entre os construtos.

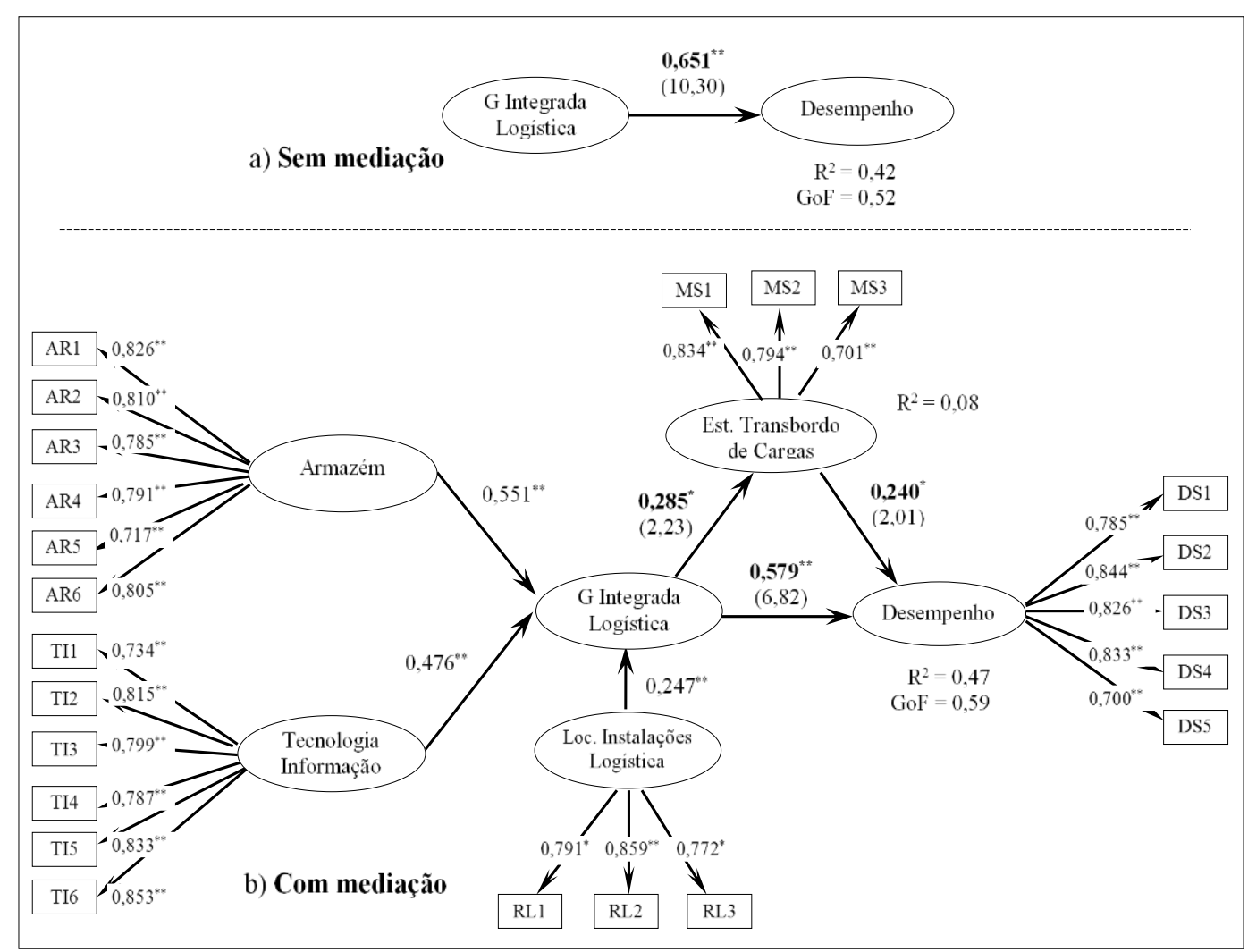

Figura 3. Modelo Teórico-Empírico.

O símbolo de * indica que a o coeficiente é significante a 5\%; ** a $1 \%$. 


\section{Avaliações das relações estruturais do modelo de mensuração}

Os resultados dos ajustes e significâncias estatísticas das relações estruturais do modelo de mensuração examinados pela técnica de modelagem em equação estrutural, o PLS-PM, foram:

Na Figura 3, observaram-se as significâncias estatísticas dos construtos armazém, tecnologia da informação e localização das instalações logísticas, com isso, denotando a importância deles no gerenciamento integrado da logística, conforme argumentado por Coyle, Bardi e Langley (2003), Meixell e Norbis (2008) e Chopra e Meindl (2001).

Para testar a hipóteses de que a variável estação de transbordo de cargas medeia a relação entre gestão integrada da logística e desempenho logístico, realizaram-se duas abordagens em modelagem em equações estruturais. A primeira, com o relacionamento direto entre gestão e desempenho, conforme ilustrado no item a da Figura 3, e a segunda, o relacionamento entre gestão integrada e desempenho logístico, com a mediação da estação de transbordo de cargas, conforme colocado no item b da Figura 3.

O modelo teórico de relacionamento direto, mostrado no item a da Figura 3, ajustou-se muito bem, com valores de $\mathrm{R}^{2}$ e GoF iguais a 0,42 e 0,52 e superiores aos recomendados de 0,36 e 0,26, respectivamente. $\mathrm{O}$ coeficiente estrutural para o caminho direto de gestão integrada e desempenho foi de 0,651 , com valor t igual a 10,08, estatisticamente significante para $\alpha \leq 0,01$, suportando a hipótese $\mathrm{H}_{1}$.

O item b da Figura 3 ilustra o resultado do modelo estrutural do relacionamento após a incorporação da estação de transbordo de cargas como variável moderadora na relação entre gestão integrada e desempenho. Os dados do modelo se ajustaram melhor do que os do anterior. Os valores de ajustes, dados por $\mathrm{R}^{2}$ e $\mathrm{GoF}$, foram de 0,47 e 0,59 , respectivamente. O coeficiente estrutural para o caminho direto de gestão integrada e desempenho foi de 0,579 , com valor t igual a 6,82 , estatisticamente significante para $\alpha \leq 0,01$, suportando a hipótese $\mathrm{H}_{1 \mathrm{a}}$.

Para o caminho indireto entre gestão integrada e estação de transbordo, o coeficiente estrutural foi de 0,285 e valor $t$ igual a 2,23, com significância estatística $\alpha \leq 0,05$, indicando suporte para a hipótese $\mathrm{H}_{2}$. Para o caminho indireto entre estação de transbordo e desempenho logístico, o coeficiente estrutural foi de 0,240 e valor $t$ igual a 2,01, estatisticamente significante para $\alpha \leq 0,05$, suportando a hipótese $\mathrm{H}_{3}$.

Para a determinação do impacto da mediação da estação de transbordo de cargas, foram utilizadas as regressões lineares não padronizadas, mostradas na Tabela 3. Inicialmente, foram comparados os caminhos da gestão integrada e desempenho logístico dos dois modelos. No item a da Figura 3, o caminho foi positivo e significante. Após a introdução da variável estação de transbordo, indicada no item b da Figura 3, o caminho teve o coeficiente estrutural reduzido e continuou como estatisticamente significante. Este resultado, na tipologia de Baron e Kenny (1986), conduziu à mediação do tipo parcial e foi suporte para a hipótese $\mathrm{H}_{4}$ em nível de significância estatística $\alpha \leq 0,05$.

Entretanto, para se obter maior clareza da significância estatística ou mesmo estabelecer contraprova do resultado obtido (Baron \& Kenny, 1986; Mackinnon, 2008), foram aplicados os testes Z de Sobel (1982), Aroian (1947) e Goodman (1960). Os resultados são mostrados na Tabela 3. 
Tabela 3

Testes de Mediação

\begin{tabular}{llll}
\hline Testes & Valor-Z & Erro padrão & Valor-p \\
\hline Sobel & 1,94 & 0,043 & 0,053 \\
Aroian & 1,88 & 0,044 & 0,061 \\
Goodman & 2,00 & 0,041 & 0,045 \\
\hline
\end{tabular}

É possível observar, na Tabela 3, que os testes de Sobel (1982), Aroian (1947) e Goodman (1960) apresentaram resultados próximos do limite da significância estatística para $\alpha \leq 0,05$, denotando a mediação parcial.

Na busca de melhor clareza da tipologia, recorreu-se à classificação de Iacobucci et al. (2007). Assim, com base na estatística da distribuição normal reduzida, $Z$, e significância dos caminhos da variável independente $(\mathrm{X})$, variável moderadora $(\mathrm{M})$ e variável dependente $(\mathrm{Y})$, foram obtidos os seguintes resultados.

1. No teste de Goodman (1960), em que a estatística $Z$, os caminhos $\mathrm{X} \rightarrow \mathrm{M}$ e $\mathrm{M} \rightarrow \mathrm{Y}$ e $\mathrm{X} \rightarrow \mathrm{Y}$ foram significantes para $\alpha \leq 0,05$, indicou-se que significativa porção da variância de $Y$ devido a $X$ foi explicada pelo caminho indireto.

2. Nos testes de Sobel (1982) e Aroian (1947), em que a estatística $Z$ foi não significante, mas os caminhos $\mathrm{X} \rightarrow \mathrm{M}$ e $\mathrm{M} \rightarrow \mathrm{Y}$ e $\mathrm{X} \rightarrow \mathrm{Y}$ foram significantes para $\alpha \leq 0,05$, verificou-se que a variância de $\mathrm{Y}$ devido a $\mathrm{X}$ foi explicada tanto pelo caminho direto como pelo caminho indireto, na presença do efeito direto.

Portanto, da mesma forma que Baron e Kenny (1986), segundo a classificação tipológica de Iacobucci et al. (2007), a mediação é parcial, independentemente da estatística $\mathrm{Z}$ ser positiva ou negativa.

\section{Conclusões e Sugestões para Prosseguimento}

Nas empresas brasileiras do ramo de fertilizantes, em nível de significância estatística $\alpha \leq 0,05$, foi verificado que o desempenho logístico pode ser impactado tanto diretamente, pela gestão integrada, como indiretamente, pela estação de transbordo de cargas.

O resultado obtido mostrou a aderência do modelo teórico, construído a partir das hipóteses formuladas, e a evidência estatística da estação de transbordo de cargas como variável mediadora parcial entre a gestão integrada e o desempenho logístico. Esta evidência pode ser corroborada nos seguintes fatos: (a) a oferta de transportes rodoviários era insuficiente para atender à demanda das empresas do ramo de fertilizantes. Apesar dos empecilhos da intermodalidade, os gestores das empresas de fertilizantes preferiam utilizá-las para não colocar os fretes rodoviários sob pressão de aumento dos valores; (b) os gestores tinham a confiança de que os esforços de empresas públicas e privadas na ampliação ou construção de novas estações de transbordos seriam futuramente compensados, e; (c) os obstáculos existentes para a utilização da intermodalidade não eram vistos como impeditivos, mas como um recurso com deficiências temporárias e ainda administráveis que, se melhoradas, poderiam trazer maior competitividade.

Em resumo, a utilização plena da intermodalidade para cargas do produto fertilizante ainda tem um longo caminho a ser percorrido. 

a seguir.

As implicações deste resultado sob as perspectivas gerenciais e teórico-empíricas são comentadas

\section{Perspectivas gerenciais}

O estudo constatou, sob o ponto de vista dos gestores logísticos das empresas brasileiras do ramo de fertilizantes, que o custo logístico foi considerado a principal preocupação. Os gestores procuravam modal de transportes de menor frete para permitir a manutenção de preços competitivos, pois a margem de lucro do produto fertilizante é baixa e qualquer custo adicional poderia tirá-lo do mercado.

As demais preocupações constatadas foram: (a) a comunicação entre os condutores das cargas que, basicamente, era realizada pelo telefone celular, tanto para o modal ferroviário como o rodoviário. A utilização do Global Positioning System (GPS) era feita pela área administrativa da empresa transportadora para o gerenciamento da posição dos caminhões e otimização da frota (Bowersox, Closs, Cooper, \& Bowersox, 2014); (b) consideravam as estações de transbordos de cargas como de baixa produtividade, especialmente, em relação às velocidades de operações de manejo, carregamento e descarregamento, bem como o desperdício do produto durante o processo de transbordo (Caixeta \& Martins, 2001); e, (c) tinham a percepção de que os fretes de transportes ferroviários eram realizadas com base nos fretes de transportes rodoviários. Isto causava-lhes desconfiança de que os fretes não se davam num processo de livre negociação, em razão do modelo de concessão da malha ferroviária brasileira. As concessionárias ferroviárias poderiam estar se utilizando da posição de monopólio para reduzir a oferta de vagões e demandar fretes maiores. Este era um desafio que precisava ser vencido, que consistia em ter um transporte ferroviário eficiente, o que, segundo os gestores logísticos, havia no período em que o modal ferroviário não era privatizado (Teller et al., 2007).

Apesar das barreiras e entraves para a utilização das estações de transbordos de cargas, verificouse que os respondentes pretendiam aumentar a utilização da intermodalidade nos transportes de fertilizantes. Ainda, tinham a esperança de que as ações tomadas pelas empresas públicas e privadas em investir em estações de transbordo de cargas constituir-se-iam em fonte de redução de custos e melhoria do nível da qualidade do serviço prestado em termos de velocidade e flexibilidade de entregas.

De fato, as empresas públicas e privadas têm feito investimentos nas estações de transbordos ou em instalações portuárias, tanto para reduzir custos como para melhorar a qualidade dos serviços em termos de flexibilidade e velocidade de entrega. Exemplo disso são os investimentos na construção da estação multimodal de cargas em Passo Fundo (RS), pela empresa privada América Latina Logística, para "recebimento, Armazenagem e transportes de fertilizantes e grãos" (Torres, 2006, p. 15), e, em Conchas (SP), pela parceria pública (governo do Estado) e empresa privada, a Companhia Nacional de Armazéns Gerais Alfandegados (CNAGA), para receber comboios com cargas de grãos do centro-oeste brasileiro com destino ao porto de Santos e retorno com cargas de fertilizantes e calcário nas barcaças (Tomazela, 2014).

Para o modal rodoviário, uma alternativa de reduzir os custos logísticos do fertilizante é combinar o escoamento dos grãos para os portos ou armazéns com o retorno de fertilizantes (ou outros insumos como sementes e herbicidas) para as propriedades rurais, especialmente, nos períodos em que os preços internacionais dos fertilizantes estiverem em baixa, de tal maneira que compensem os custos de armazenagens (Daher, 2009; Michelon, 2007).

Construir infraestrutura logística para agronegócios é demorado e exige grandes investimentos. As crises financeiras têm levado empresas privadas e públicas a alongarem o tempo de entrega das construções ou a adiarem investimentos em instalações de transbordo de cargas, ferrovias, rodovias e armazéns. Associada à ineficiência da infraestrutura logística, também está a morosidade dos procedimentos burocráticos, de natureza tributária, para a movimentação dos produtos (Agência Nacional de Transportes Terrestres [ANTT], 2011). 


\section{Perspectivas de pesquisas teórico-empíricas}

Como se observou neste estudo, o custo dos transportes foi considerado primordial para a competitividade do produto fertilizante. Todavia não houve evidências de que assertivas relacionadas aos níveis de serviços prestados, como agilidade de entrega, qualidade da informação e escolha de modal de baixa taxa de poluente, eram consideradas importantes para a gestão integrada da logística, dado que foram excluídas do modelo. Segundo Morash, Drsoge e Vickery (1996), fatores de níveis de serviços prestados, como velocidade e flexibilidade de entregas, são considerados estratégicos para a competitividade das empresas. Exemplo disso pode ser constatado mesmo em empresas de commodities, como as produtoras de aço, que são forçadas a ser enxutas para competir em custo, entrega e qualidade.

A competitividade dessas empresas depende dos seus processos produtivos e logísticos (Glader, 2006), bem como das estações de transbordos como meio facilitador para utilizar os restritos tempos de janelas para movimentação de produtos nos grandes centros urbanos (Mitrovic-Minic \& Laporte, 2006), reduzir custos e melhorar os níveis de serviços.

Todavia, em uma economia globalizada, as preocupações atuais vão além dos investimentos pecuniários em infraestrutura logística. O sistema logístico deve proporcionar, às movimentações de cargas, aderência com a realidade estrutural e as peculiaridades exigidas pela sociedade, como a sustentabilidade (Lin, 2011), sob pena de ser incluído nos mecanismos de barreiras não tarifárias (Silveira, 2011).

Para competir no mercado internacional, a logística brasileira tem de inovar a fim de resolver os problemas de gargalos, melhorar níveis de serviços e aumentar a produtividade e questões de sustentabilidade de natureza ambiental, social e econômica. Exemplos de inovações logísticas, de natureza ambiental e econômica, podem ser vistos em projetos como Marco Polo, da União Europeia (European Commission, 2012); Modal Shift, no Japão (Ogawa, 2004); e, no Brasil, avanços nas leis ambientais que regulam as estações de transbordos, nas instalações portuárias públicas de pequeno porte (Decreto n. 8.033, 2013) e na parceria do governo brasileiro com a Confederação Nacional das Indústrias para reduzir em 5\% as emissões de carbono até o ano de 2020 (Adjuto, 2012). No campo acadêmico, tem-se observado trabalhos de gestão logística relacionados à análise do ciclo de vida dos produtos, segundo a norma ISO 14040 e 14044 (Bovolenta \& Biaggioni, 2010). Ainda, pode-se notar inovação logística de natureza social como na legislação trabalhista conhecida como a Lei do Motorista (Lei n. 12.619, 2012).

Estudos acadêmicos em gestão logística têm focado nos modos de transportes. Todavia, com o fortalecimento dos corredores logísticos, decorrentes de investimentos em estações intermodais (Decreto n. 8.033, 2013) e em sistemas de transportes (Ministério dos Transportes, n. d.), a gestão logística deve se inovar para atender às novas demandas do mercado. Por exemplo, enquanto, no Japão, a logística é baseada na eliminação dos gargalos e desenvolvimento de terminais intermodais, nos Estados Unidos, tem-se como base o desenvolvimento de corredores nacionais e hubs de cargas intermodais (Horn \& Toshinori, 2005). Mudar o paradigma de gerenciar a logística pode ser um caminho para avançar nas práticas logísticas e o meio acadêmico pode dar grande contribuição.

Em face das dificuldades de investimentos em infraestrutura logística e das pressões internacionais para preços cada vez mais competitivos, de modo sustentável, o gestor logístico brasileiro, do produto fertilizante, tem um papel importante na administração da matriz de transportes, de tal sorte, a obter o melhor de cada modal ou a combinação deles à necessária competitividade das empresas. Assim, o treinamento e a capacitação gerencial deverão ser constantemente renovados, dado que gestão logística necessita ser desenvolvida e aprimorada o tempo todo.

Por fim, como prosseguimento, há inúmeras alternativas. Não obstante, para não perder o foco, são sugeridos: (a) desenvolver modelos concorrentes para avaliar as estações de transbordos de cargas; (b) aumentar o tamanho da amostra ou ampliá-la, com a incorporação de segmentos similares como agrotóxicos e sementes, e; (c) realizar estudos contínuos, de concepção longitudinal. Neste caso, a 
amostra de empresas poderia ser menor, no entanto com as mesmas empresas e, assim, as possíveis variações causais poderiam ser detectadas com maior facilidade.

\section{Referências}

Adjuto, G. (2012, agosto 21). CNI Firma acordo com governo para reduzir emissões de carbono. Agência Brasil: Empresa Brasil de Comunicação. Recuperado de http://agenciabrasil.ebc.com.br/noticia/2012-08-21/cni-firma-acordo-com-governo-para-reduziremissoes-de-carbono-na-industria

Agência Nacional de Transportes Terrestres. (2011). Entraves burocráticos, exigências legais e tributárias do transporte multimodal (Relatório), Brasília, DF. Recuperado de http://www.antt.gov.br/html/objects/_downloadblob.php?cod_blob=3767

Aroian, L. A. (1947). The probability function of the product of two normally distributed variables. Annals of Mathematical Statistics, 18(2), 265-271.

Associação Nacional para Difusão de Adubos. (n.d.b). Empresas associadas. Recuperado de http://www.anda.org.br/index.php?mpg=02.02.00\&ver=por

Associação Nacional para Difusão de Adubos. (n.d.a). Principais indicadores do setor de fertilizantes. Recuperado de http://www.anda.org.br/index.php?mpg=03.00.00

Ballou, R. H. (2010). Gerenciamento da cadeia de suprimentos / Logística empresarial (5a ed.). Porto Alegre: Bookman.

Banco Nacional de Desenvolvimento Econômico e Social. (2010b, junho 23). BNDES modifica classificação de porte de empresa. Recuperado de http://www.bndes.gov.br/SiteBNDES/bndes/bndes_pt/Institucional/Sala_de_Imprensa/Noticias/ 2010/institucional/20100622_modificacao_porte_empresa.html

Banco Nacional de Desenvolvimento Econômico e Social. (2010a, janeiro). Panorama atual e perspectivas de desenvolvimento do setor de fertilizantes no Brasil. Informe Setorial, (16). Recuperado http://www.bndes.gov.br/SiteBNDES/export/sites/default/bndes_pt/Galerias/Arquivos/conheci mento/setorial/informe-16AI.pdf

Baron, R. M., \& Kenny, D. A. (1986). The moderator-mediator variable distinction in social psychological research: conceptual, strategic, and statistical considerations. Journal of Penality and Social Psychology, 51(6), 1173-1182. doi: 10.1037/0022-3514.51.6.1173

Blauwens, G., Vandaele, N., Voorde, E. Van de, Vernimmen, B., \& Witlox, F. (2006). Towards a modal shift in freight transport? A business logistics analysis of some policy measures. Transport Reviews: A Transnational Transdisciplinary Journal, 26(2), 239-251. doi: $10.1080 / 01441640500335565$

Bovolenta, F. C., \& Biaggioni, M. A. M. (2010). Balanço energético comparativo para rotas de escoamento de soja. Eng. Agríc., Jaboticabal: Engenharia Agrícola, 30(4), 587-599. doi: 10.1590/S0100-69162010000400003

Bowersox, D. J., \& Closs, D. J. (2001). Logística empresarial. São Paulo: Atlas.

Bowersox, D. J., Closs, D. J., Cooper, M. B., \& Bowersox, J. C. (2014). Gestão logística da cadeia de suprimentos. Porto Alegre: Bookman. 
Bowersox, D. J., \& Daugherty, P. J. (1995). Logistics paradigms: the impact of information technology. Journal of Business Logistics, 16(1), 65-80.

Caixeta, J. V., Filho, \& Martins, R. S. (2001). Gestão logística do transporte de cargas. São Paulo: Atlas.

Campbel, J. F. (1992). Location and allocation for distribution systems with transshipments and transportation economies of scale. Annals of operations research, 40(1), 77-99. doi: 10.1007/BF02060471

Chin, W. W. (1998). The partial least squares approach to structural equation modeling. In G. A. Marcoulides (Ed.), Modern methods for business research (pp. 295-336). Mahwah, NJ, USA: Lawrence Erlbaum Associates.

Chopra, C., \& Meindl, P. (2001). Supply chain management: strategy, planning, and operation. New Jersey: Prentice Hall.

Cohen, J. (1977). Statistical power analysis for the behavioral sciences (Rev. Ed.). New York: Academic Press.

Council of Supply Chain Management Professionals. (n.d.). CSCMP supply chain management. Retrieved from: http://cscmp.org/about-us/supply-chain-management-definitions

Coyle, J. J., Bardi, E. J., \& Langley, C. J., Jr. (2003). The management of business logistics - a supply chain perspective. Mason: South-Western.

Coyle, J. J., Novak, R. A., Gibson, B., \& Bardi, E. J. (2011). Transportation: a supply chain perspective. Mason, OH, USA: South-Western College Pub.

Daher, E. (2009, maio/junho). Quando comprar fertilizantes. DBO Agrotecnologia, p. 27.

Dalmás, S. R. S. P. da, Lobo, D. S. da, \& Rocha, W. F., Jr. da (2009). A logística de transporte agrícola multimodal da região oeste paranaense. Revista Informe Gepec, 13(2), 154-169.

Decreto n. 8.033 de 27 de junho de 2013. (2013). Regulamenta o disposto na Lei no 12.815, de 5 de junho de 2013, e as demais disposições legais que regulam a exploração de portos organizados e de instalações portuárias. Brasília, DF. Recuperado de http://presrepublica.jusbrasil.com.br/legislacao/1035367/decreto-8033-13

Diamantopoulos, A., \& Winklhofer, H. M. (2001). Index construction with formative indicators: an alternative to scale development. Journal of Marketing Research, 38(2), 269-277. doi: $10.1509 / j m k r .38 .2 .269 .18845$

Dillman, D. A. (2000). Mail and internet surveys: the tailored design method. New York: John Wiley \& Sons, Inc.

European Commission. (n.d.). Marco Polo - New ways to a green horizon. Retrieved from http://ec.europa.eu/transport/marcopolo/

Fawcett, S. E., Stanley, L. L., \& Smith, S. R. (1997). Developing a logistics capability to improve the performance of international operations. Journal of business logistics, 18(2), 101-127.

Fleury, P. F., Wanke, P., \& Figueiredo, K. (2000). Logística empresarial - a perspectiva brasileira. São Paulo: Atlas.

Fornell, C., \& Larker, D. (1981). Evaluating structural equation models with unobservable variables and measurement error. Journal of Marketing Research, 18(1), 39-50. 
Garg, R., \& Prakash, S. (1985). Time minimizing transshipment problem. Indian Journal of Pure and Applied Mathematics, 16(5), 449-460.

Garrido, J. (2011, abril). O desafio de acabar com a ineficiência. Revista Valor Econômico, Setorial logística, 8-18.

Glader, P. (2006, junho 21). Quantos níveis hierarquicos tornam uma empresa enxuta? The Wall Street Journal America, p. B12.

Goodman, L. A. (1960). On the exact variance of products. Journal of the American Statistical Association, 55(292), 708-713. doi: 10.1080/01621459.1960.10483369

Griffis, S. E., Goldsby, J. T., Cooper, M., \& Closs, D. J. (2007). Aligning logistics performance measures to the information needs of the firm. Journal of Business Logistics, 28(2), 35-56. doi: $10.1002 / j .2158-1592.2007 . t b 00057 . x$

Hair, F. J., Jr., Anderson, R. E., Tathan, R. L., \& Black, W. C. (2005). Análise multivariada de dados. Porto Alegre: Bookman.

Henseler, J., Ringle, C. M., \& Sinkovics, R. R. (2009). The use of partial least squares path modeling in international marketing. International Marketing, 20, 277-319. doi: 10.1108/S14747979(2009)0000020014

Horn, B. E, \& Toshinori, N. (2005). Intermodal logistics policies in the EU, the US and Japan. Transport Policy Studies' Review, 7(4), 2-14.

Iacobucci, D., Saldanha, N., \& Deng, X. (2007). A meditation on mediation: evidence that structural equations models perform better than regressions. Journal of Consumer Psychology, 17(2), 140154. doi: 10.1016/S1057-7408(07)70020-7

Instituto Brasileiro de Geografia e Estatística. (2014, janeiro 9). IBGE confirma safra recorde em 2013 $e$ prevê produção ainda maior em 2014. Recuperado de http://saladeimprensa.ibge.gov.br/noticias?view=noticia\&id=1\&busca=1\&idnoticia=2561

Jeffs, V. P., \& Hills, P. J. (1990). Determinants of modal choice in freight transport - a case study. Transportation, 17(1), 29-47. doi: 10.1007/BF02125502

Jöreskog, K. G., \& Wold, H. (1982). The ML and PLS techniques for modeling with latent variables: historical and comparative aspects. In K. G. Jöreskog \& H. Wold (Eds.), Systems under indirect observation: causality, structure, prediction. Part I. (pp. 1-54). Netherlands: North-Holland Publishing Company.

Kim, G., Shin, B., \& Grover, V. (2010). Investigating two contradictory views of formative measurement in information systems research. MIS Quartely, 34(2), 345-365.

Lei n. 9.611 de 19 de fevereiro de 1998. (1998). Dispõe sobre o transporte multimodal de cargas e dá outras providências. Brasília, DF. Recuperado de: http://www.planalto.gov.br/ccivil_03/Leis/L9611.htm

Lei n. 12.619 de 30 de abril de 2012. (2012). Dispõe sobre o exercício da profissão de motorista; altera a Consolidação das Leis do Trabalho - CLT, aprovada pelo Decreto-Lei no 5.452, de 1o de maio de 1943, e as Leis nos 9.503, de 23 de setembro de 1997, 10.233, de 5 de junho de 2001, 11.079, de 30 de dezembro de 2004, e 12.023, de 27 de agosto de 2009, para regular e disciplinar a jornada de trabalho e o tempo de direção do motorista profissional; e dá outras providências. Brasília, DF. Recuperado de http://www.planalto.gov.br/ccivil_03/_ato2011-2014/2012/lei/112619.htm

Lin, C. Y. (2011). A review of research on environmental issues in the logistics industry. Information Management and Business Review, 3(1), 19-26. 
Mackinnon, D. P. (2008). Introduction to statistical mediation analysis (Multivariate Applications Series). Routledge - Taylor \& Francis Group, 477p.

Meixell, M. J., \& Norbis, M. (2008). A review of transportation mode choice and carrier selection literature. International Journal of Logistics Management, 19(2), 183-211. doi: 10.1108/09574090810895951

Mentzer, J. T., Min, S., \& Bobbit, L. M. (2004). Toward a unified theory of logistics. International Journal of Physical Distribution \& Logistics Management, 34(8), 606-627. doi: 10.1108/09600030410557758

Miao, Z., Yang, F., Fu, K., \& Xu, D. (2012). Transshipment service through crossdocks with both soft and hard time windows. Annals Operations Research, 192(1), 21-47. doi: 10.1007/s10479-0100780-4

Michelon, E. R. S. (2007). A utilização de carga de retorno no transporte de soja: característica, dificuldades e vantagens (Projeto de estágio profissionalizante). Universidade de São Paulo, São Paulo, SP, Brasil. Recuperado de http://esalqlog.esalq.usp.br/files/biblioteca/arquivo973.pdf

Ministério dos Transportes. (n. d.). Conheça o PNLT. Recuperado de http://www.transportes.gov.br/conteudo/3254

Mitrovic-Minic, S., \& Laporte, G. (2006). The pick-up and delivery problem with time Windows and transshipment. Infor, 44(3), 217-227.

Morash, E. A., Drsoge, C., \& Vickery, S. K. (1996). Strategic logistics capabilities for competitive advantage and firm success. Journal of Business Logistics, 17(1), 1-22.

Nicolella, A. C., Dragone, D. S., \& Bacha, C. J. C. (2005). Determinantes da demanda de fertilizantes no Brasil no período de 1970 a 2002. Revista de Economia e Sociologia Rural, 43(1), 81-100. doi: 10.1590/S0103-20032005000100005

Ogawa, K. (2004). Modal shift - A key component of Japan's response to global warning. Classnk Magazine, $\quad 56, \quad 6-9 . \quad$ Retrieved $\quad$ from http://www.classnk.or.jp/hp/pdf/publications/Publications_image/NKMagazine56.pdf

Petter, S., Straub, D., \& Rai, A. (2007). Specifying formative constructs in information systems research. MIS Quartely, 31(4), 623-656.

Promoting Innovative Intermodal Freight Transport. (2007). D 4.1: European benchmarks in intermodal transport. Retrieved from http://www.promit-project.net/UploadedFiles/Deliverables/D4_1.pdf

Rodrigue, J. P., Comtois, C., \& Slack, B. (2006). The geography of transport systems. New York: Taylor $\&$ Francis e-Library.

Salin, D. L. (2013). Soybean transportation guide: Brazil 2012. United States Department of Agriculture. Retrieved http://www.ams.usda.gov/AMSv1.0/getfile?dDocName=STELPRDC5103745

Secretaria de Portos. (n. d.). Terminais de uso privado. Recuperado de http://www.portosdobrasil.gov.br/assuntos-1/investimentos/terminais-de-uso-privado

Sheffi, Y., Eskandari, B., \& Koutsopoulos, H. N. (1988). Transportation mode choice based on total logistics costs. Journal of Business Logistics, 9(2), 137-154.

Silva, L. A. T. (2008). Logística no comércio exterior. São Paulo: Edições aduaneiras Ltda. 
Silveira, G. (2011, agosto 1). Barreiras não tarifárias afetam soja brasileira. Recuperado de http://blogs.ruralbr.com.br/sojaporglaubersilveira/2011/08/01/barreiras-nao-tarifarias-afetamsoja-brasileira/

Silveira, G. (2012, outubro 23). Porque importamos fertilizantes se temos tantas jazidas no Brasil? Recuperado de http://blogs.ruralbr.com.br/sojaporglaubersilveira/2012/10/23/porqueimportamos-fertilizantes-se-temos-tantas-jazidas-no-brasil/

Simchi-Levi, D., Kaminsky, P., \& Simchi-Levi, E. (2003). Cadeia de suprimentos - projetos e gestão. Porto Alegre: Bookman.

Smith, D., \& Langfield-Smith, K. (2004). Structural equation modeling in management accounting research: critical analysis and opportunities. Journal of Accounting Literature, 23, 49-86.

Sobel, M. E. (1982). Asymptotic intervals for indirect effects in structural equations models. In S. Leinhart (Ed.), Sociological methodology 1982 (pp. 290-312). San Francisco: Jossey-Bass.

Stock, G. N., Greis, N. P., \& Kasarda, J. D. (1999). Logistics, strategy and structure: a conceptual framework. International Journal of Physical Distribution \& Logistics Management, 29(4), 224239. doi: $10.1108 / 09600039910273948$

Teller, S. T., Guimarães, M. F., \& Roessing, A. C. (2007, julho). Perfil para a infra-estrutura de transportes para o escoamento de soja no Brasil. Anais do Congresso da SOBER, UEL, Londrina, PR, Brasil, 45.

Tenenhaus, M., Vinzi, V. E., Chatelin, Y.-M., \& Lauro, C. (2005). PLS - Path modeling. Computational Statistics \& Data Analysis, 48, 159-205. Retrieved from https://studies2.hec.fr/jahia/webdav/site/hec/shared/sites/tenenhaus/acces_anonyme/home/article s/PLS_PM_5.pdf. doi: 10.1016/j.csda.2004.03.005

Tomazela, J. M. (2014, maio 27). O Porto fantasma da Tietê-Paraná. Jornal O Estado de São Paulo, Caderno de Economia, Negócios, p. B11.

Torres, C. L. (2006). O Intermodal a passos largos. São Paulo: Valor Setorial, Logística.

Wetzels, M., Odekerken-Schröder, G., \& Van Oppen, C. (2009). Using PLS path modeling for assessing hierarchical construct models: guidelines and empirical illustration. MIS Quarterly, 33(1), 177195.

Woxenius, J. (1997, September). Terminals: a barrier for intermodality? Proceedings of the Nordic Transport Research's Ebeltoft: Conference on Intermodal Freight Transport, Ebeltoft, Denmark. Retrieved from http://www.gu.se/digitalAssets/1344/1344850_1997_aarhus_terminals.pdf 


\section{APÊNDICE A}

Tabela A1

\section{Resultados de Confiabilidade e Validação}

\begin{tabular}{|c|c|c|c|c|c|}
\hline \multicolumn{3}{|c|}{ CONSTRUTO / ASSERTIVAS } & \multirow{2}{*}{$\begin{array}{c}\text { Média } \\
3,57\end{array}$} & \multirow{2}{*}{$\begin{array}{l}\text { DP } \\
1,07\end{array}$} & \multirow{2}{*}{$\begin{array}{l}\text { Carga } \\
0,826\end{array}$} \\
\hline \multirow{6}{*}{ 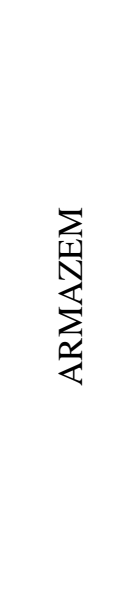 } & AR1 & $\begin{array}{l}\text { Para a minha empresa, o número de terminais é suficiente para o } \\
\text { transporte intermodal }\end{array}$ & & & \\
\hline & AR2 & $\begin{array}{l}\text { Para a minha empresa, os terminais e pontos de transbordo disponíveis } \\
\text { apresentam alta produtividade }\end{array}$ & 3,57 & 1,02 & 0,811 \\
\hline & AR3 & $\begin{array}{l}\text { Para a minha empresa, a quantidade de produto que é perdida durante o } \\
\text { processo de transferência do trem para o caminhão ou vice-versa é baixa }\end{array}$ & 3,97 & 1,34 & 0,785 \\
\hline & AR4 & $\begin{array}{l}\text { A maioria dos terminais de granéis que minha empresa utiliza foi } \\
\text { projetada especificamente para trabalhar com fertilizantes }\end{array}$ & 3,52 & 1,16 & 0,791 \\
\hline & AR5 & $\begin{array}{l}\text { Para a minha empresa, existem pontos de transbordos suficientes e } \\
\text { preparados para o transporte intermodal }\end{array}$ & 2,52 & 1,15 & 0,718 \\
\hline & AR6 & $\begin{array}{l}\text { Para a minha empresa, existem terminais suficientes para operar com } \\
\text { armazéns e carregamento de fertilizantes }\end{array}$ & 3,28 & 1,07 & 0,805 \\
\hline \multirow{6}{*}{ 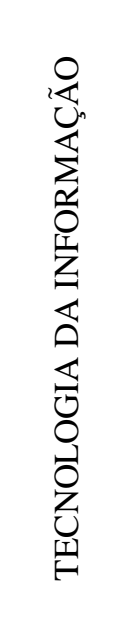 } & TI1 & $\begin{array}{l}\text { A minha empresa conta com a facilidade para troca eletrônica de } \\
\text { informações com prestadores de serviços de transporte rodoviário }\end{array}$ & 4,35 & 1,12 & 0,734 \\
\hline & TI2 & $\begin{array}{l}\text { A minha empresa conta com a facilidade para troca eletrônica de } \\
\text { informações com prestadores de serviços de transporte ferroviários }\end{array}$ & 3,80 & 1,38 & 0,815 \\
\hline & TI3 & $\begin{array}{l}\text { A minha empresa conta com a facilidade para troca eletrônica de } \\
\text { informações com prestadores de serviços de armazéns }\end{array}$ & 3,65 & 1,34 & 0,799 \\
\hline & TI4 & $\begin{array}{l}\text { Durante o transporte intermodal, para a minha empresa, é fácil conseguir } \\
\text { rastrear a localização da carga no trecho rodoviário }\end{array}$ & 3,22 & 1,24 & 0,787 \\
\hline & TI5 & $\begin{array}{l}\text { Durante o transporte intermodal, para a minha empresa, é fácil conseguir } \\
\text { rastrear e localizar a carga dentro trecho ferroviário }\end{array}$ & 3,20 & 1,30 & 0,833 \\
\hline & TI6 & $\begin{array}{l}\text { Durante o transporte intermodal, para a minha empresa, é fácil conseguir } \\
\text { informações e relatórios eletrônicos com a posição do estoque no } \\
\text { terminal }\end{array}$ & 3,58 & 1,30 & 0,853 \\
\hline \multirow{3}{*}{ 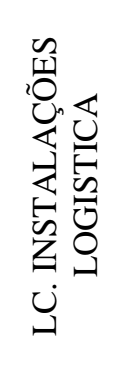 } & RL1, & $\begin{array}{l}\text { Para a minha empresa, no planejamento da localização de uma nova } \\
\text { planta é levada em consideração a disponibilidade de transporte } \\
\text { ferroviário na região }\end{array}$ & 5,27 & 1,09 & 0,791 \\
\hline & RL2 & $\begin{array}{l}\text { Para a minha empresa, quando é feita a importação de matéria-prima, é } \\
\text { levada em conta a disponibilidade de armazéns na região portuária }\end{array}$ & 5,09 & 1,29 & 0,870 \\
\hline & RL3 & $\begin{array}{l}\text { Para a minha empresa, no projeto de nova planta, na existência de } \\
\text { ferrovia, opta-se normalmente por construir a planta o mais próximo do } \\
\text { ponto de demanda }\end{array}$ & 5,35 & 0,71 & 0,772 \\
\hline \multirow{3}{*}{ 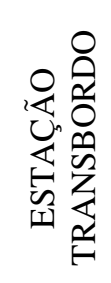 } & ET1 & $\begin{array}{l}\text { Na minha empresa, para médias e longas distâncias, sempre que } \\
\text { possível, opta-se pelo transporte ferroviário ou intermodal }\end{array}$ & 5,30 & 0,97 & 0,834 \\
\hline & ET2 & $\begin{array}{l}\text { Para a minha empresa, de maneira geral, para médias e longas distâncias, } \\
\text { o transporte intermodal é de custo menor que o rodoviário }\end{array}$ & 5,31 & 1,06 & 0,794 \\
\hline & ET3 & $\begin{array}{l}\text { Na minha empresa, a troca de modais é sempre um problema devido à } \\
\text { demora }\end{array}$ & 5,26 & 0,76 & 0,701 \\
\hline
\end{tabular}




\section{Tabela A1 (continuação)}

\begin{tabular}{|c|c|c|c|c|c|}
\hline \multicolumn{3}{|c|}{ CONSTRUTO / ASSERTIVAS } & Média & DP & Carga \\
\hline \multirow{5}{*}{ 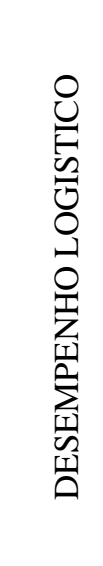 } & DS1 & $\begin{array}{l}\text { Para a minha empresa, o transporte rodoviário causa pouco problema de } \\
\text { perda do produto transportado }\end{array}$ & 4,13 & 1,29 & 0,786 \\
\hline & DS2 & $\begin{array}{l}\text { Para a minha empresa, o transporte ferroviário causa pouca perda do } \\
\text { produto transportado }\end{array}$ & 3,90 & 1,15 & 0,844 \\
\hline & DS3 & $\begin{array}{l}\text { Para a minha empresa, o transporte intermodal apresenta perda de } \\
\text { produto dentro de patamares aceitáveis }\end{array}$ & 4,24 & 1,13 & 0,826 \\
\hline & DS4 & $\begin{array}{l}\text { A minha empresa, ao utilizar o transporte intermodal, tem obtido custos } \\
\text { competitivos no transporte rodoviário quando comparado com outros } \\
\text { transportes }\end{array}$ & 4,73 & 1,13 & 0,833 \\
\hline & DS5 & $\begin{array}{l}\text { A minha empresa tem aumentado sua participação dentro da matriz de } \\
\text { transportes da empresa, uma vez que entende que a mesma pode ser um } \\
\text { redutor de custos }\end{array}$ & 5,29 & 1,03 & 0,700 \\
\hline
\end{tabular}

Nota. O questionário adotou a escala de Likert de 1 a 6 (Discordo Totalmente a Concordo Totalmente). 


\section{APÊNDICE B}

\section{Regressões Lineares para a Mediação}

\begin{tabular}{|c|c|c|c|c|c|c|c|c|}
\hline \multirow{3}{*}{\multicolumn{2}{|c|}{$\begin{array}{l}\text { REGRESSÕES } \\
\text { LINEARES }\end{array}$}} & \multicolumn{3}{|c|}{ Coeficientes } & \multicolumn{2}{|c|}{ Valor } & \multicolumn{2}{|c|}{ Colinearidade } \\
\hline & & \multicolumn{2}{|c|}{ Não padronizados } & \multirow{2}{*}{$\begin{array}{c}\text { Padronizado } \\
\text { B }\end{array}$} & \multirow[t]{2}{*}{$\mathbf{t}$} & \multirow[t]{2}{*}{$\mathbf{p}$} & \multirow[t]{2}{*}{ Tolerância } & \multirow[t]{2}{*}{ VIF } \\
\hline & & B & Erro padrão & & & & & \\
\hline \multirow[t]{3}{*}{$\mathrm{R}_{1}$} & \multicolumn{8}{|c|}{ Variável Dependente: DESEMPENHO $\rightarrow R^{2}=0,388 ; R_{\text {ajustado }}^{2}=0,381$} \\
\hline & Constante & 1,405 & 0,418 & & 3,36 & 0,001 & & \\
\hline & G. Integrada (c) & 0,790 & 0,106 & 0,623 & 7,43 & 0,000 & 1,000 & 1,000 \\
\hline \multirow[t]{3}{*}{$\mathrm{R}_{2}$} & \multicolumn{8}{|c|}{ Variável Dependente: TRANSBORDO $\rightarrow R^{2}=0,073 ; R_{\text {ajustado }}^{2}=0,063$} \\
\hline & Constante & 4,230 & 0,412 & & 10,28 & 0,000 & & \\
\hline & G. Integrada (a) & 0,275 & 0,105 & 0,271 & 2,63 & 0,010 & 1,000 & 1,000 \\
\hline \multicolumn{9}{|c|}{ Variável Depender } \\
\hline & Constante & 0,130 & 0,597 & & 0,22 & 0,828 & & \\
\hline & E. Transbordo (b) & 0,302 & 0,105 & 0,241 & 2,88 & 0,005 & 0,927 & 1,079 \\
\hline & G. Integrada (c') & 0,707 & 0,106 & 0,558 & 6,66 & 0,000 & 0,927 & 1,079 \\
\hline
\end{tabular}

Nota. A letra (a) indica o coeficiente não padronizado para a relação entre X-M; (b) para a relação entre M-Y (quando X é também uma preditora de Y); (c) denota a relação entre X-Y e; (c') denota a relação entre X-Y, após o efeito de M. 